\title{
The Outcomes of Recurrent Retinal Detachment Surgery and the Effects of the First Surgeon to the Final Outcomes
}

\author{
Nüks Retina Dekolmanı Cerrahisi Sonuçlarımız ve Illk \\ Cerrahın Sonuca Etkisi
}

(D) Hatice Nur Tarakçıoğlu, (1D Abdullah Özkaya²

${ }^{1}$ Department of Ophthalmology, Bakırköy Sadi Konuk Training and Research Hospital, İstanbul, Turkey

${ }^{2}$ Department of

Ophthalmology, Memorial

Şişli Hospital, İstanbul,

Turkey; Department of

Ophthalmology, Istanbul

Aydin University Medical

School, Istanbul, Turkey

Cite this article as: Tarakçıŏlu HN, Özkaya A. The Outcomes of Recurrent Retinal Detachment Surgery and the Effects of the

First Surgeon to the Final Outcomes. Bosphorus Med J 2020;7(2):39-44.

Received: 03.01 .2020 Accepted: 21.05.2020

Correspondence: Dr. Abdullah Özkaya. Istanbul Aydin University Medical School, Florya, Istanbul, Istanbul, Turkey Phone: +905054529270

e-mail: abdozkaya@gmail.com OPEN ACCESS

\section{ABSTRACT}

Objectives: To evaluate the outcomes of vitreoretinal surgery in patients with recurrent retinal detachment (RD) and compare whether these outcomes differ regarding the surgeon who carried out the first surgery.

Methods: The medical records of the recurrent RD patients who underwent vitrectomy between January 2014 and December 2016 were reviewed for this retrospective single-surgeon study. The included patients had a postoperative follow-up period of at least 12 months. If the first surgery was carried out by the same surgeon, then the patients were included in group $A$, and if the patient was a referral patient and the first surgery was carried out by another surgeon, then the patient was included in group B. Primary outcome measure was the anatomical success at month 12.

Results: There were 12 eyes (20.7\%) in group A and 46 eyes (79.3\%) in group B. The anatomical success after a single secondary operation was $67.2 \%$ in the whole group. It was $75.0 \%$ and $65.2 \%$ in groups $A$ and $B$, respectively $(p=0.4)$. Final anatomical success after multiple surgeries was achieved in 46 of the 58 patients $(77.6 \%)$ in the whole group. The final anatomical success was $91.7 \%$ and $73.9 \%$ in group $A$ and $B$, respectively $(p=0.1)$.

Conclusion: In conclusion, we detected a positive trend in anatomical outcomes after vitrectomy surgery in the subgroup recurrent RD patients that were operated by the same surgeon who carried out the first operation.

Keywords: Proliferative vitreoretinopathy; retinal detachment; vitrectomy.

\section{ÖZET}

Amaç: Nüks retina dekolmanı olan hastalarda vitreoretinal cerrahinin sonuçlarını değerlendirmek ve ilk ameliyatı yapmış olan cerraha göre nüks cerrahisinin sonuçlarını karşılaştırmak.

Yöntem: Bu çalışmada, Ocak 2014 ile Aralık 2016 tarihleri arasında tek cerrah tarafından nüks retina dekolmanı tanısı ile vitrektomi yapılmış olan hastaların kayıtları geriye dönük olarak tarandı. Cerrahi sonrası takip süresi en az 12 ay olan hastalar çalışmaya alındılar. İlk cerrahisi aynı cerrah tarafından yapılmış olan hastalar A grubu, ilk cerrahisi farklı bir cerrah tarafından yapılmış olan hastalar ise B grubu adı altında değerlendirildiler. Çalışmanın temel sonlanım noktası 12. aydaki anatomik başarı oranı idi.

Bulgular: A grubunda 12 hasta (\%20.7) ve B grubunda 46 hasta (\%79.3) vardı. Tüm grupta tek ikincil cerrahi sonrası anatomik başarı oranı \%67.2 idi. A grubunda anatomik başarı \%75.0, B grubunda ise \%65.2 idi ( $p=0.4$ ). Çoklu cerrahiler sonrası son anatomik başarıya ise 58 hastanın 46'sında (\%77.6) ulaşıldı. Yine son anatomik başarı A grubunda $\% 91.7$, B grubunda ise \%73.9 idi ( $p=0.1)$.

Sonuç: Illk cerrahi ile aynı cerrah tarafından opere edien nüks retina dekolmanı hastalarında anatomik başarı oranı açısından olumlu olarak yorumlanabilecek bir trend mevcuttu.

Anahtar sözcükler: Proliferatif vitreoretinopati; retina dekolmanı; vitrektomi. 
$\mathrm{T}^{\mathrm{h}}$

he treatment of recurrent retinal detachment (RD) is usually administered with vitreoretinal surgery, especially in case of proliferative vitreoretinopathy (PVR). ${ }^{[1-3]}$ The primary target of vitreoretinal surgery is to relieve vitreoretinal traction, reattach the retina and seal the retinal break. If the patient has recurrent $\mathrm{RD}$, then vitreoretinal traction and PVR are probably the most important issues. ${ }^{[3-6]}$ Combining vitrectomy with scleral buckle, membrane peeling, retinotomy/retinectomy, using liquid perfluorocarbons, and using silicone oil or perfluorocarbon gases as tamponades are important advances introduced for complicated cases of RD. ${ }^{[6]}$ In a study conducted by Mansouri et al., ${ }^{[7]}$ the effects of initial treatment whether it was vitrectomy, or scleral buckling, or vitrectomy + scleral bucking was evaluated. The subgroup of the patients who were operated with scleral buckling required fewer number of secondary operations and silicone oil injections in that study. In part agreement with Mansouri et al., we differently aimed to evaluate the outcomes of vitrectomy in patients with recurrent RD and compare whether these outcomes differ in regards to the surgeon who performed the first surgery.

\section{Methods}

This was a single surgeon, retrospective, comparative study. The medical records of the patients with recurrent $\mathrm{RD}$ who underwent vitrectomy between January 2014 and December 2016 were reviewed. Local review board approval was obtained for this study. This study was adherent to the tenets of the Declaration of Helsinki, and written informed consent was obtained from all of the included patients for the surgeries.

The recurrent RD patients who had a minimum follow-up period of 12 months after surgery were included. If silicone oil was preferred as a tamponade in the first surgery and if the follow-up was not $\geq 6$ months after silicone oil removal, or had a history of trauma were excluded from this study. The patients underwent vitrectomy or scleral buckling surgeries previously and the first surgery was unsuccessful in all of the included patients.

Age, sex, best corrected visual acuity (BCVA), the first surgeon of the patients, functional and anatomical outcomes, and complications were recorded. A projection chart was used for the measurement of BCVA, biomicroscopic anterior and posterior segment examination was performed, and intraocular pressure (IOP) was measured using applanation tonometry. The post-operative examinations were performed on the $1^{\text {st }}$ day, in the 1 st week, $1^{\text {st }}, 3^{\text {rd }}, 6^{\text {th }}$, and $12^{\text {th }}$ month.
In postoperative month 12 , if a patient had a postoperative BCVA $\geq 1.0$ LogMAR, ${ }^{[8]}$ then he/she was accepted to have functional success and if a patient had an attached retina in month $12^{\text {th }}$, he/she was accepted to have an anatomical success. If the retina was totally or partially detached, then the case was accepted to have an anatomical failure. In some of the patients, silicone oil was permanently left, and these patients were accepted to have an anatomical failure.

\section{Surgical Technique}

All of the second procedures were performed by a single surgeon (AO). A 23-gauge transconjunctival vitrectomy with the Constellation system (Alcon Surgical, Ft. Worth, TX) and a wide-field viewing system (Eibos, Haag Streit, Wedel, Germany) were used. If the patient was phakic and had a prominent cataract, phacoemulsification was performed before the vitrectomy. Four sclerotomies were created for infusion, vitreous cutter, endoillumination, and one 25-gauge sclerotomy for chandelier light were prepared and silicone oil (if present) and/or the remaining vitreous (if present) was completely removed. Vitreous base was shaved carefully and retinal breaks were marked via endodiathermy and vitreoretinal traction was released around them. The subretinal membranes which caused stiffness and all of the preretinal membranes were removed. If retinal stiffness was not resolved after removal of the membranes, then retinotomy/ retinectomy was performed. A flute needle was used to drain the existing subretinal fluid from an existing break with or without the assistance of a heavy perfluorocarbon fluid. Endolaser photocoagulation was applied to all of the breaks. The amount of additional barrier laser photocoagulation was changed according to the retinal situation. For example, if a patient did not have any peripheral retinal degeneration of membranes at the superior half of the retina, then only 180-degree barrier laser photocoagulation was applied to the lower half of the retina, or 360-degree barrier laser photocoagulation was applied if there were diffuse retinal degenerations. Air-fluid exchange was performed and suitable tamponade was exchanged with air. Lastly, all of the sclerotomies were checked and were sutured with $7 / 0$ polyglactin suture if leakage was present. The endotamponade choice was made according to the surgeons' preferences; however, silicone oil was preferred in the vast majority of the cases as they were very complicated. Silicone oil was planned to be removed between month three and 12 postoperatively. The patients were divided into two subgroups as the same surgeon and different surgeon for further evaluation. If the 
first surgery was performed by the same surgeon, then the patients were included in group A, and if the patient was a referral patient and the first surgery was performed by another surgeon rather than $\mathrm{AO}$, then the patient was included in group B.

Primary outcome measure was the anatomical success between the two surgeon groups in postoperative month 12 .

\section{Statistical Analysis}

Statistical Package for the Social Sciences (SPSS) software (version 21.0) was used for the analyses. For statistical analysis, BCVA values were converted to LogMAR values. Normality was assessed using the Kolmogorov-Smirnov test and the data were found to be normally distributed. Repeated measures test was used for comparing the BCVA values between baseline and the follow-up visits. Independent t-test was used to assess the differences between the two subgroups. A chi-square test was used in the comparison of categorical variables. A p-value $<0.05$ was considered statistically significant.

\section{Results}

Fifty-eight eyes of 58 patients were included in this study. Forty patients $(69.0 \%)$ were men and $18(31.0 \%)$ were women. The mean age was $57.4 \pm 13.2$ years (range 21-82 years). The mean follow-up duration was $17.1 \pm 5.3$ months (between 12-34 months). There were 12 eyes (20.7\%) in group A and 46 eyes (79.3\%) in group B. The detailed distribution of surgical techniques in group A was no membrane peeling or retinotomy/retinectomy in four patients (33.3\%), only membrane peeling in four patients (33.3\%), membrane peeling and minimal, relaxing retinotomies in three patients (25.0\%), and inferior 180-degree retinectomy in one patient (8.3\%). In group B, 12 eyes (26.1\%) required no membrane peeling or retinotomy/retinectomy, 20 eyes $(43.5 \%)$ required only membrane peeling, 10 eyes (21.7\%) required membrane peeling and minimal, relaxing retinotomies, three eyes (6.5\%) required inferior 180-degree retinectomy, and one eye (2.2\%) 360-degree retinectomy. The required surgical technique distribution was similar between the two groups $(p=0.9)$. The general characteristics of the two groups are summarized in Table 1.

\section{Anatomical Outcomes}

The reason for the first recurrence was PVR (45 eyes, 77.6\%) and undertreated/missed retinal tears/holes (13 eyes, $22.4 \%)$. The anatomical success after a single secondary operation was obtained in 39 of the 58 patients $(67.2 \%)$ in the whole group. It was $75.0 \%$ and $65.2 \%$ in group A and B, respectively $(\mathrm{p}=0.4)$. Final anatomical success was achieved in 46 of the 58 patients $(77.6 \%)$ in the whole group. The final anatomical success was $91.7 \%$ and $73.9 \%$ in group A and B, respectively $(p=0.1)$. Final anatomical success was obtained in 11 of the 12 eyes group A. The remaining one patient was left with permanent silicone oil endotamponade. Thirtyfour of the 46 eyes had attached retina at the final visit in group B, eight (17.4\%) of the remaining patients were left with permanent silicone oil endotamponade, two of them had detached retina (4.3\%), and two of them showed prephthisis at the final visit.

\section{Table 1. General characteristics of the study groups}

\begin{tabular}{|c|c|c|c|}
\hline & Group A, n, 12 & Group B, n, 46 & $\mathbf{p}$ \\
\hline Gender (Female/Male) & $3 / 9$ & $15 / 31$ & 0.5 \\
\hline Lens status (Phakic/Pseudophakic/Aphakic) & $2 / 10 / 0$ & $12 / 33 / 1$ & 0.6 \\
\hline First surgery (PPV/Scleral buckle) & $11 / 1$ & $40 / 6$ & 0.5 \\
\hline Baseline BCVA, LogMAR & $1.92 \pm 0.86$ & $2.12 \pm 0.70$ & 0.4 \\
\hline Tamponade (SO/C3F8) & $11 / 1$ & $42 / 4$ & 0.9 \\
\hline Functional Success (BCVA $\geq 1.0$ LogMAR at the final visit) (\%) & 50.0 & 23.9 & 0.07 \\
\hline Final anatomical Success (\%, retinal attachment at the final visit) & 91.7 & 73.9 & 0.1 \\
\hline
\end{tabular}




\section{Visual Outcomes}

The mean baseline BCVA was 1.92 \pm 0.86 LogMAR (range 0.53.0) and 2.12 \pm 0.70 LogMAR (range 0.5-3.0) group A and $B$, respectively $(\mathrm{p}=0.4)$ (Table 2$)$. The change in mean BCVA from baseline to months 3, 6, 9 and 12, and last visit was statistically better in both group A ( $p<0.05$ for all) and group $B(p<0.001$ for all), respectively. The change in mean BCVA at month 12 was 5.4 LogMAR lines and 4.9 LogMAR lines in group $A$ and $B$, respectively $(p=0.7)$. The functional success rate was $50 \%$ in group A and $23.9 \%$ in group $B$ $(\mathrm{p}=0.07)$.

\section{Lens Status, Tamponades, and Intraocular Pressure}

Baseline lens status and the distribution of the preferred tamponade were similar between the two groups (Table 1) ( $\mathrm{p}=0.6$ and $\mathrm{p}=0.9$ ).

The mean baseline IOP and IOP at the last follow-up visit was $13.1 \pm 4.5 \mathrm{mmHg}$ (between $3-18 \mathrm{mmHg}$ ) and $12.4 \pm 4.2$ $\mathrm{mmHg}$ (between 2-18 $\mathrm{mmHg}$ ) in group $\mathrm{A}(\mathrm{p}=0.5)$. The mean baseline IOP and IOP at the last follow-up visit was $11.5 \pm 4.4$ $\mathrm{mmHg}$ (between $1-20 \mathrm{mmHg}$ ) and $13.5 \pm 4.6 \mathrm{mmHg}$ (between $1-25 \mathrm{mmHg})$ in group $\mathrm{B}(\mathrm{p}=0.01)$. The IOP at the last follow-up visit was $<6 \mathrm{mmHg}$ in one eye $(8.3 \%)$ in group $\mathrm{A}$ and in 3 eyes $(6.5 \%)$ in group $B(p=0.8)$. Any of the eyes in each group did not show a phthisis bulbi. Early IOP elevation was detected in three eyes (25.0\%) group A and 11 eyes $(23.9 \%)$ in group $B(p=0.9)$. None of the eyes in group A and five eyes (10.9\%) in group B showed prolonged IOP elevation and were treated with antiglaucomatous drugs $(\mathrm{p}=0.3)$.

The number of required reoperations (after the operation for recurrent $\mathrm{RD}$ ) was $0.16 \pm 0.57$ (range $0-2$ ) and $0.21 \pm 0.51$ (range $0-2)$ in group $A$ and $B$, respectively $(p=0.7)$.

\section{Complications}

Mild-transient anterior chamber reaction (16.6\% in group A versus $19.5 \%$ in the group $B, p=0.7$ ) and transient corneal edema ( $25.0 \%$ in group $A$ versus $17.3 \%$ in the group $B, p=0.5$ ) were the early postoperative complications. Late postop- erative complications in group A were limited to epiretinal membrane formation in three eyes $(25.0 \%)$. In group B late complications were corneal endothelial decompensation in one eye (2.2\%), macular hole formation in five eyes (10.8\%), and epiretinal membrane formation in nine eyes (19.5\%).

\section{Discussion}

We evaluated the outcomes of vitrectomy in patients with recurrent $\mathrm{RD}$ in this study. In addition, we divided the patients into subgroups according to the surgeons who performed the first surgery and compared the outcomes in this regard. The anatomical success rate after a single operation in group A and B of the present study was $75 \%$ and $65.2 \%$ and final anatomical success after multiple surgeries increased to $91.7 \%$ and $73.9 \%$, respectively. Although there was not a statistically significant difference between the two groups, there was a positive trend in group A in regard to the anatomical outcomes. The change in BCVA from baseline to month 12 was similar between the two groups; however, the functional success rate nearly reached statistical significance ( $\mathrm{p}=0.07$ ) and was $50 \%$ and $23.9 \%$ in group $A$ and $B$, respectively. According to our results, we may propose that the experience of the first surgeon is important and affects the outcome of the following reoperations.

The overall second surgery anatomical success rate was $67.2 \%$ in our study. The most important reason for primary anatomical failure for RD surgery is PVR and it occurs in approximately $5-10 \%$ of the patients. ${ }^{[9-10]}$ The primary success rate of vitrectomy in patients with recurrent $\mathrm{RD}$ with PVR was reported between as low as $14 \%$ to as high as $80 \%$. ${ }^{[10]}$ The final anatomical success rate was increased by $10 \%$ and reached to $77.6 \%$ after multiple surgeries in the present study. The final anatomical success of vitrectomy for recurrent and complicated retinal detachment cases was reported as $93 \%$ by Quiram et al., $80 \%$ by Pournaras et al., $90-100 \%$ by Mancino et al., around $70 \%$ by Wei et al. and $65 \%$ by Karakaya et al. in previous studies. ${ }^{[9-12]}$ Our final anatomical success rate was similar to the studies reported above. Pournaras et al. evaluated the anatomical and functional outcomes for recurrent retinal detachment surgery

Table 2. Visual acuity levels of the two study groups at different time points

\begin{tabular}{lcccccc} 
& Baseline & Month 3 & Month 6 & Month 9 & Month 12 & Last visit \\
\hline Group A, LogMAR & $1.92 \pm 0.86$ & $1.58 \pm 0.38$ & $1.37 \pm 0.53$ & $1.25 \pm 0.57$ & $1.38 \pm 0.88$ & $1.38 \pm 0.88$ \\
Group B, LogMAR & $2.12 \pm 0.70$ & $1.83 \pm 0.65$ & $1.70 \pm 0.60$ & $1.63 \pm 0.55$ & $1.63 \pm 0.61$ & $1.63 \pm 0.65$
\end{tabular}


in a retrospective study, which included 70 patients. ${ }^{[11]}$ The used surgical technique was not uniform in the study, and the anatomic success rate was reported as $80 \%$. The authors reported that the existence of PVR and need for retinectomy was associated with negative anatomical outcome. Quiram et al. investigated the outcomes of vitrectomy with inferior retinectomy in patients with recurrent RD. ${ }^{[10]}$ Fiftysix patients were included in the retrospective study, and the authors used a standard surgical technique in which they performed an inferior retinectomy if retinal traction was persistent after adequate membrane peeling. Silicone oil or gas tamponade was used for the patients. The mean follow-up period of the study was reported as 25 months and $75 \%$ of the included patients were referral patients (in our study, $79.3 \%$ were operated by another surgeon). In contrast to our study, some of the included patients were previously operated more than once and the mean number of previous operations was 1.8. The prior surgeries included pneumatic retinopexy along with scleral buckling and vitrectomy in contrast to our surgery in which pneumatic retinopexy failures were not included. The baseline visual acuity of the included patients was very poor and 46 of the 56 patients had a vision of counting fingers or worse, which was also worse than our study. The anatomical success rate was reported to be $60 \%$ after the first surgery and improved to $93 \%$ with additional surgeries and vision was stabilized or improved in $70 \%$ of the patients at the last follow-up visit. Additionally, the authors reported that radical anterior vitreous base dissection and lensectomy and use of silicone oil tamponade were significantly related with the better anatomical outcome, whereas adding a scleral buckle to the first surgery did not have a positive effect on the retinectomy procedure. Lesnoni et al. ${ }^{[13]}$ evaluated the vision improvement and patient satisfaction after multiple surgeries for recurrent $\mathrm{RD}$ in their retrospective study. They used a telephone interview for assessing the patients' visual performance and satisfaction. Sixty-two patients were included in the study and the follow-up period of the study was 19 months. The mean number of operations was 2.9 and recurrences were 1.45. At the final follow-up, $75.8 \%$ of the patients had a visual acuity of $\geq 5 / 200$ and $20.9 \%$ had $\geq 20 / 200$. Additionally, $56.5 \%$ of the patients gained $\geq 2$ lines of vision, and interestingly, after the interview, using phone call, $53 \%$ of the patients told that they believed that operated eye had a better vision postoperatively. Mancino et al. ${ }^{[9]}$ conducted a study in which they assessed the outcomes of inferior retinotomy and silicone oil endotamponade for recurrent $\mathrm{RD}$. Their included group of recurrent RD patients were similar to our study, all of whom underwent previously vitrectomy or scleral buckle. A total of 33 eyes were evaluated retrospectively, and 12 of them were previously underwent a scleral buckle and 21 of them underwent vitrectomy. The mean follow-up period was quite long and 42 months. The whole group of the study showed a significant improvement regarding visual acuity and mean BCVA increased from 1.28 to 0.74 LogMAR at the last follow-up visit and the anatomical success rate was over $90 \%$. The patients who previously underwent a scleral buckle showed visual improvement from 0.98 LogMAR to 0.52 LogMAR and the anatomical success was $100 \%$ at the last follow-up visit. The patients who previously underwent vitrectomy also showed visual improvement from 1.46 LogMAR to 0.87 LogMAR and the anatomical success was $91 \%$ at the last follow-up visit. Wei et al.[14] compared the outcomes of scleral bucking and vitrectomy in patients with recurrent inferior $\mathrm{RD}$ in their retrospective study. A total of 103 patients were included in the study and all of the patients had recurrent inferior RD in the silicone oil-filled eyes. There were 49 patients in the scleral buckle group and 54 eyes in the re-vitrectomy group of the study. The anatomical success rate after a mean follow-up period of 13 months after was $65.3 \%$ in the scleral buckle group and $72.2 \%$ in the re-vitrectomy group. The authors also performed a subgroup analysis between the patients who required second surgery $<1$ month (early group) and 1-6 months (late group). The anatomical success rate was similar between the early and late period $70.8 \%$ and $73.3 \%$ in the re-vitrectomy group, whereas it was statistically different and was $80.8 \%$ and $47.8 \%$ in the scleral buckle group, respectively. Mansouri et al. conducted a similar study to Wei et al. ${ }^{[7]}$ and compared the outcomes of retinal detachment surgery with vitrectomy between the group of patients who previously underwent scleral buckle, or vitrectomy, or combination of scleral buckle and vitrectomy. After a single operation, the anatomical success rate was similar among the three groups and was $80.0 \%, 82.9 \%$, and $82.2 \%$ in the scleral buckle, vitrectomy and scleral buckle+vitrectomy subgroups, respectively.

The retrospective design was the main limitation of this study. The number of included patients was quite good for a single-surgeon study. Also, we compared the outcomes concerning the first surgeon of the patients and achieved some interesting results in this regard. 


\section{Conclusion}

In conclusion, we detected a positive trend both in anatomical and functional outcomes after vitrectomy surgery in the subgroup recurrent $\mathrm{RD}$ patients, which were operated by the same surgeon. In contrast, the patients who were previously operated by another surgeon showed a negative trend in the outcomes. This study may outline the importance of the first surgery of RD patients and the first surgery of RD patients had to be carried out by experienced hands or at least in the supervision of senior surgeons.

\section{Disclosures}

Ethics Committee Approval: The study was approved by ethical committee of Bakırköy Dr. Sadi Konuk Training and Research Hospital numbered as 2020/31-03022020.

Peer-review: Externally peer-reviewed.

Conflict of Interest: None declared.

Authorship Contributions: Concept - H.N.T., A.Ö.; Design H.N.T., A.Ö.; Supervision - A.Ö.; Materials - H.N.T., A.Ö.; Data collection \&/or processing - A.Ö.; Analysis and/or interpretation - H.N.T., A.Ö.; Literature search - H.N.T., A.Ö.; Writing A.Ö.; Critical review - H.N.T., A.Ö.

\section{References}

1. Moysidis SN, Thanos A, Vavvas DG. Mechanisms of inflammation in proliferative vitreoretinopathy: from bench to bedside. Mediators Inflamm 2012;2012:815937. [CrossRef]

2. Sadaka A, Giuliari GP. Proliferative vitreoretinopathy: current and emerging treatments. Clin Ophthalmol 2012;6:1325-33.

3. Di Lauro S, Kadhim MR, Charteris DG, Pastor JC. Classifications for Proliferative Vitreoretinopathy (PVR): An Analysis of Their Use in Publications over the Last 15 Years. J Ophthalmol 2016;2016:7807596. [CrossRef]

4. Garnier S, Rahmi A, Grasswil C, Kodjikian L. Three hundred and sixty degree retinotomy for retinal detachments with severe proliferative vitreoretinopathy. Graefes Arch Clin Exp Ophthalmol 2013;251:2081-5. [CrossRef]

5. Lai FH, Lo EC, Chan VC, Brelen M, Lo WL, Young AL. Combined pars plana vitrectomy-scleral buckle versus pars plana vitrectomy for proliferative vitreoretinopathy. Int Ophthalmol 2016;36:217-24. [CrossRef]

6. Khan MA, Brady CJ, Kaiser RS. Clinical management of proliferative vitreoretinopathy: an update. Retina 2015;35:165-75.

7. Mansouri A, Almony A, Shah GK, Blinder KJ, Sharma S. Recurrent retinal detachment: does initial treatment matter? $\mathrm{Br} J$ Ophthalmol 2010;94:1344-7. [CrossRef]

8. Ozkaya A, Tarakcioglu HN, Kemer B. The Outcomes of Primary Retinal Detachment Surgery with 23-gauge Vitrectomy in $\mathrm{Pa}$ tients without Severe Proliferative Vitreoretinopathy: A Single Surgeon Case Series. OR 2018;9:1-6. [CrossRef]

9. Mancino R, Aiello F, Ciuffoletti E, Di Carlo E, Cerulli A, Nucci C. Inferior retinotomy and silicone oil tamponade for recurrent inferior retinal detachment and grade C PVR in eyes previously treated with pars plana vitrectomy or scleral buckle. BMC Ophthalmol 2015;15:173. [CrossRef]

10. Quiram PA, Gonzales CR, Hu W, Gupta A, Yoshizumi MO, Kreiger $\mathrm{AE}$, et al. Outcomes of vitrectomy with inferior retinectomy in patients with recurrent rhegmatogenous retinal detachments and proliferative vitreoretinopathy. Ophthalmology 2006;113:2041-7. [CrossRef]

11. Pournaras C, Tsika C, Brozou C, Tsilimbaris MK. Surgical and visual outcome for recurrent retinal detachment surgery. J Ophthalmol 2014;2014:810609. [CrossRef]

12. Karakaya M, Albayrak S, Pehlivanoglu S, Ozkaya A, Gocgil NA. 5-Fluorouracyl added infusion fluid in patients with recurrent rhegmatogeneous retinal detachment. Saudi J Ophthalmol. 2019;33:56-60. [CrossRef]

13. Lesnoni G, Rossi T, Gelso A, Nistril A. Patient satisfaction and vision improvement after multiple surgery for recurrent retinal detachment. Eur J Ophthalmol 2005;15:102-8. [CrossRef]

14. Wei Y, Wu G, Xu K, Wang J, Zu Z, Wang R. The outcomes of scleral buckling versus re-vitrectomy for the treatment of recurrent inferior retinal detachment in silicone oil tamponade eyes. Acta Ophthalmol 2016;94:e624-e628. [CrossRef] 